\title{
СРАВНИТЕЛЬНЫЙ АНАЛИЗ РАЗЛИЧНЫХ МЕТОДИК КОРРЕКЦИИ ПРЕДДВЕРИЯ РТА НА БЕЗЗУБОЙ НИЖНЕЙ ЧЕЛЮСТИ ПРИ ПОДГОТОВКЕ К ПРОТЕЗИРОВАНИЮ
}

\section{COMPARATIVE ANALYSIS OF VARIOUS TECHNIQUES FOR CORRECTING THE VESTIBULE OF THE MOUTH ON THE TOOTHLESS LOWER JAW IN PREPARATION FOR PROSTHETICS}

N. Maksimova

Summary. Purpose. Comparative analysis of the effectiveness of various surgical techniques for correcting the vestibule of the oral cavity in elderly and senile patients with complete absence of teeth in the lower jaw based on the analysis of data from the clinical course of the postoperative period.

Methods. The article analyzes in a comparative aspect the effectiveness of different methods of surgical correction of the vestibule of the mouth in 61 elderly and senile patients with complete absence of teeth in the lower jaw in preparation for prosthetics with a complete removable plate prosthesis based on the analysis of the clinical course of the early postoperative period.

Results and Summary. According to the results of the study, it was revealed that in patients who underwent surgical correction of the vestibule of the oral cavity using a modified technique, the postoperative period was less painful, and the time for healing and epithelialization of the wound surface was reduced. The study allows us to recommend this technique for effective correction of the shallow vestibule of the oral cavity in elderly patients with complete absence of teeth in the lower jaw at the stage of preprosthetic preparation of the oral cavity.

Keywords: attached gum, vestibuloplasty, the depth of the vestibule of the oral cavity, techniques for deepening the vestibule.

\author{
Максимова Наталья Владимировна \\ ФГБОУ ВО «Рязанский медицинский университет \\ имени \\ Академика И.П. Павлова» Министерства \\ здравоохранения Российской Федерации (2. Рязань) \\ natali2411@bk.ru
}

\begin{abstract}
Аннотация. Цель. Сравнительный анализ эффективности различных хирургических методик коррекции преддверия полости рта у пациентов пожилого и старческого возраста с полным отсутствием зубов на нижней челюсти на основании анализа данных клинического течения постоперационного периода.
\end{abstract}

Материал и методы. В статье анализируется в сравнительном аспекте эффективность разных методик хирургической коррекции преддверия рта у 61 пациента пожилого и старческого возраста с полным отсутствием зубов на нижней челюсти при подготовке к протезированию полным съемным пластиночным протезом на основании анализа клинического течения раннего постоперационного периода.

Результаты и выводы. По результатам исследования было выявлено, что у пациентов, которым хирургическая коррекция преддверия полости рта проводилась по модифицированной методике, послеоперационный период протекал менее болезненно, сократились сроки процессов заживления и эпителизации раневой поверхности. Проведенное исследование позволяет рекомендовать данную методику для эффективной коррекции мелкого преддверия полости рта у пациентов пожилого возраста с полным отсутствием зубов на нижней челюсти на этапе предпротезной подготовки полости рта.

Ключевые слова: прикрепленная десна, вестибулопластика, глубина преддверия полости рта, техники углубления преддверия.
$\mathbf{H}$ а основании данных демографических показателей в настоящее время отмечается неуклонный рост числа лиц пожилого возраста с полным отсутствием зубов [1]. Для врачей- ортопедов протезирование беззубой нижней челюсти, особенно у пациентов пожилого и старческого возраста, представляет определенные трудности из-за неблагоприятных клинических условий, проявляющихся выраженной атрофией альвеолярного отростка нижней челюсти, низким прикреплением мимической и жевательной мускулатуры и, соответственно, уменьшением глубины преддверия полости рта [2]. Согласно данным литературных источ- ников, наличие таких предрасполагающих факторов как мелкое преддверие рта, низкий уровень прикрепления уздечек губ, имеющихся подслизистых тяжей, оказывают огромное влияние на фиксацию и стабилизацию полного съемного протеза [3, 4]. На сегодняшний день представлено большое разнообразие хирургических методик по коррекции мелкого преддверия полости рта. Однако, несмотря на это, большинство методик по углублению преддверия полости рта образуют открытый раневой дефект значительных размеров, который заживает вторичным натяжением. Многие авторы отмечают, что в связи с возрастными изменениями происходит за- 
медление заживления постоперационных ран, что связано, прежде всего, с микроциркуляторными изменениями в зоне хирургического вмешательства. Актуальной представляется задача модифицирования ранее существующих хирургических методик коррекции данной патологии с целью улучшения состояния тканей протезного ложа и условий для протезирования пациентов пожилого и старческого возраста с полным отсутствием зубов.

\section{Целью исслеАования}

Сравнительный анализ эффективности различных хирургических методик коррекции преддверия полости рта у пациентов пожилого и старческого возраста с полным отсутствием зубов на нижней челюсти на основании анализа данных клинического течения постоперационного периода.

\section{Материал и методы исслеАования}

В данном клиническом исследовании приняли участие стали 61 пациент в возрасте от 65 до 75 лет без распределения по гендерному признаку. Критериями включения в исследование стали пациенты с выраженной атрофией альвеолярного отростка нижней челюсти 2-3 типа по Келлеру и слизистая оболочка протезного ложа которых соответствовала 3 классу по Суппле. При визуальном осмотре слизистая оболочка протезного ложа физиологической окраски, без рубцов и высыпаний. У всех пациентов на момент проведения хирургического лечения отсутствовало обострение общесоматических хронических заболеваний, не имелось психических отклонений, острых заболеваний слизистой оболочки полости рта, а также противопоказаний к проведению местного инъекционного обезболивания. Учитывая возраст больных, от всех было получено разрешение от их лечащих врачей по основному соматическому заболеванию на проведение хирургического вмешательства. Перед проведением хирургического вмешательства все пациенты подписали информированное добровольное согласие.

В зависимости от методики хирургического вмешательства по поводу углубления преддверия полости рта при полном отсутствии зубов на нижней челюсти пациенты были разделены на 4 группы по 17 человек в каждой. Всем больным независимо от группы исследования операцию проводили во фронтальном отделе нижней челюсти под местной инфильтрационной анестезией раствором Артикаина 4\%. Пациентам 1 группы (17 человек) проводили вестибулопластику по Кларку, 2-я группа - пациенты, которым проводилась туннельная вестибулопластика по Грудянову - Ерохину (17 человек), 3 группа (17 человек) - по Эдлану-Мейхеру и 4 группа (17 человек) - по модифицированной методике с использованием коллагеновой мембраны для закрытия раневого дефекта.

Для достижения поставленной цели применялись объективные клинические показатели в ранний послеоперационный период - повышение температуры тела, отек окружающих мягких тканей, отек слизистой оболочки в области раны, гиперемия слизистой оболочки, вид и заживление раны, и субъективные ощущения выраженность и длительность болевого синдрома. В отдаленный послеоперационный период (на 21 сутки) оценивалась глубина вновь сформированного преддверия полости рта, состояние слизистой оболочки, наличие формирования рубцов.

\section{Результаты и обсужление}

В ранний послеоперационный период жалобы на постоянную боль разной интенсивности предъявляли все пациенты 1 и 3 групп в течение 4-6 дней. На протяжении всего периода эпителизации ран пациенты этих групп жаловались на боли при приёме пищи и разговоре. Пациенты 2 группы предъявляли жалобы на умеренные боли в течение двух дней после операции. В 4 группе исследования на боли в послеоперационный период в течение первых суток после операции жаловались 2 человека (11,8\%). Послеоперационной отёк мягких тканей и инфильтрация нижней губы в области хирургического вмешательства отмечались у пациентов в 1 и 3 группах на протяжении 2-3 дней, у больных во 2 группе на протяжении 3-5 дней. В 4 группе явления послеоперационного отёка наблюдались лишь в области нижней губы в течение 1-2 дней. Повышения температуры тела до субфебрильных цифр в первый день после операции не отмечалось. Эпителизация раневой поверхности слизистой оболочки у пациентов 1 и 3 групп происходила вторичным натяжением к 8-10 дню после операции, тогда как у пациентов 3 и 4 групп эти сроки составили 5-7 дней, и заживление раневого дефекта было первичным натяжением.

Визуальный осмотр на 10-е сутки после операции установил, что у пациентов 4 группы коллагеновая мембраны заместилась вновь образованными тканями десны, с увеличением глубины преддверия полости рта в среднем на 5 мм, рана зажила без признаков рубцевания, отека тканей не наблюдалось. У пациентов 1 и 2 групп глубина сформированного на 4-5 мм преддверия полости рта сократилась до 2-3 мм. Клинический осмотр места проведения операции на 21-е сутки показал, что у пациентов 1 и 2 групп глубина преддверия во фронтальном отделе нижней челюсти сформировалась на 2-4 мм больше прежних размеров, а в 3 группе, раневая поверхность которым закрывалась 
коллагеновой мембраной, смоченной гелем Клипдент на основе гиалуроновой кислоты, преддверие сформировалось глубже на 3-5 мм от исходных значений. Хотелось бы отметить, что у пациентов 4 группы в послеоперационный период общее состояние не страдало и не наблюдалось обострение соматических фоновых заболеваний. Приём пищи проходил в обычном режиме. У пациентов 1, 2 и 3 групп в связи с более выраженными болевыми ощущениями употребление пищи было затруднено, что в 2- случаях спровоцировало обострение болезненного состояния со стороны желудочно-кишечного тракта.

\section{Выво}

Учитывая данные проведенного исследования, показывающие, что у пациентов 4 группы, которым применялась модифицированная методика коррекции преддверия полости рта послеоперационный период менее болезненен, сократились сроки процессов заживления и эпителизации, позволяет рекомендовать данную методику для эффективной коррекции мелкого преддверия полости рта у пациентов пожилого возраста с полным отсутствием зубов на нижней челюсти на этапе предпротезной подготовки полости рта.

\section{ЛИТЕРАТУРА}

1. Загорский В.А. Протезирование при полной адентии. М: Медицина -2008. 376 с.

2. Грудянов А.И. Новая методика хирургической коррекции преддверия полости рта / А.И. Грудянов, А.И. Ерохин //Пародонтология. — 2001.— № 4 (22). С. 3-6.

3. Грудянов А.И., Ерохин А.И. Хирургические методы лечения заболеваний пародонта. - М.: Медицинское информационное агентство, $2006 .-128$ c.

4. Степанов А.Е. Френулопластика, вестибулопластика и основные операции на тканях пародонта.— М.: Паритет, 2000.— 368 с.

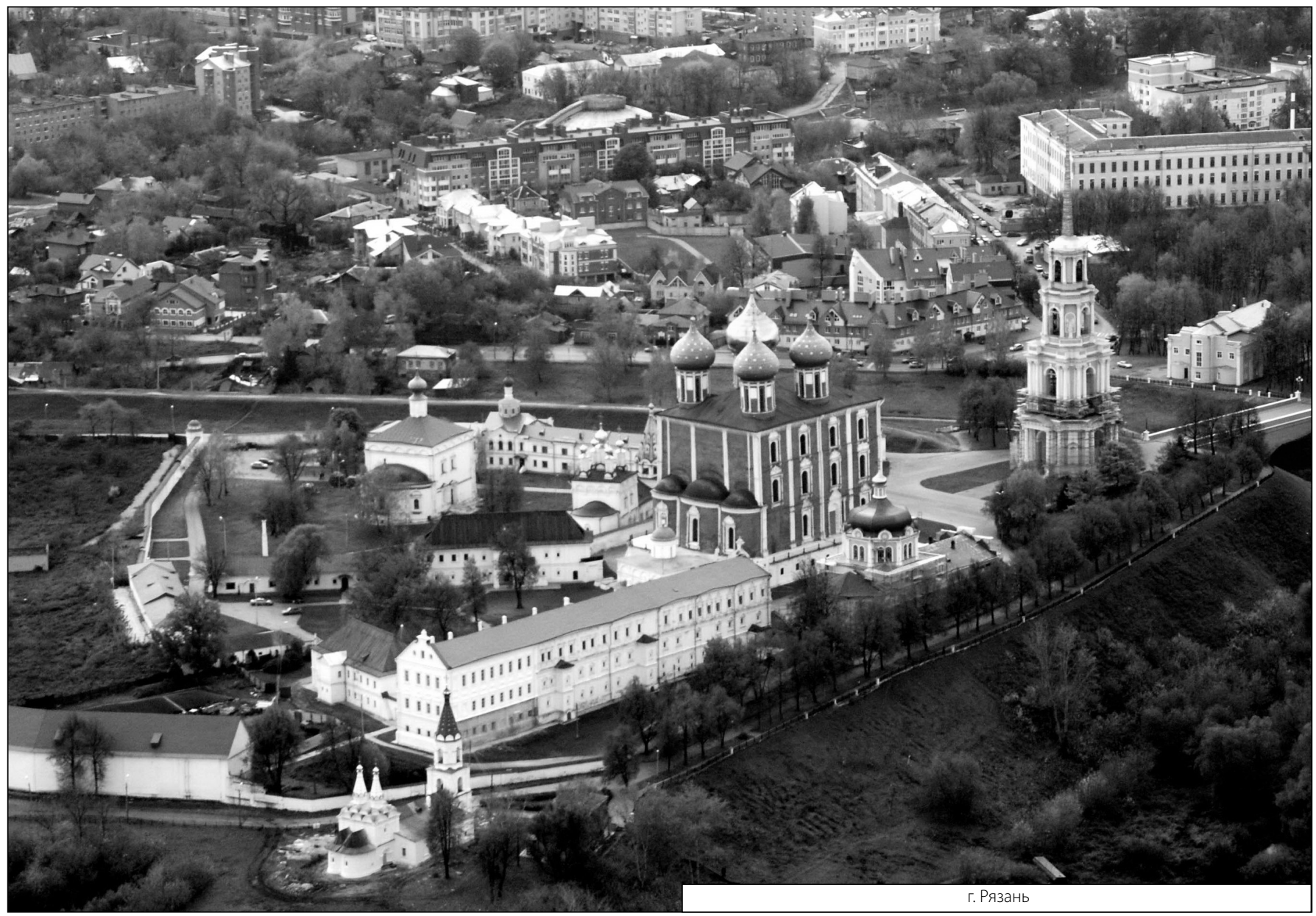

